\title{
Improved survival with higher radiation dose for esophageal squamous cell carcinoma patients treated with definitive chemoradiotherapy
}

\author{
Yuxia Deng', Chao Bian'2, Hua Tao $^{3}$ and Haijun Zhang ${ }^{1}$ \\ ${ }^{1}$ Department of Oncology, Zhongda Hospital, Medical School, Southeast University, Nanjing, China \\ ${ }^{2}$ Ningxia Medical University, Yinchuan, Ningxia, China \\ ${ }^{3}$ Department of Radiation Oncology, Jiangsu Cancer Institute and Hospital, Nanjing, China \\ Correspondence to: Haijun Zhang, email: zhanghaijunseu@163.com
}

Keywords: esophageal squamous cell carcinoma, radiotherapy, overall survival, progression-free survival

Received: January 17, 2017 Accepted: June 24, $2017 \quad$ Published: July 06, 2017

Copyright: Deng et al. This is an open-access article distributed under the terms of the Creative Commons Attribution License 3.0 (CC BY 3.0), which permits unrestricted use, distribution, and reproduction in any medium, provided the original author and source are credited.

\section{ABSTRACT}

Purpose: The optimal radiation dose for patients with esophageal squamous cell carcinoma (ESCC) has long been debated. We undertook the retrospective study to evaluate the survival impact of high dose vs standard dose in patients with stage II-III esophageal cancer treated with definitive chemoradiotherapy (CRT).

Results: A total of 137 patients were included in our study, 63 patients classified as standard-dose group and 74 as high-dose group. For the 63 patients in the standard-dose group, the median PFS and the 1-, 2-, and 3-year PFS rates were 12.6 months, $\mathbf{5 8 . 0} \%, \mathbf{2 6 . 0} \%$ and $\mathbf{1 2 . 0 \%}$, respectively; for the 74 patients in the high-dose group, they were 20.0 months, $80.1 \%, 31.0 \%$ and $20.0 \%$, respectively $(P=0.013)$. The median OS of the patients in the standard-dose group and high-dose group groups were $\mathbf{1 9 . 0}$ months and $\mathbf{2 6 . 6}$ months, respectively, and the 1-, 2- and 3-year survival rates were $78.0 \%, 39.0 \%$, and $24.0 \%$, and $89.0 \%, 61.0 \%$, and $30.0 \%$, respectively $(P=0.037)$. Besides the rate of grade $\geq 3$ acute irradiation esophagitis in the highdose group $(10.5 \%$ versus. $2.2 \%, P<0.01)$, there were no significantly differ of treatment-related toxicities between the two groups.

Materials and Methods: According to the radiation dose, patients from 2010 to 2014 were allocated into either the standard-dose group (50-50.4 Gy) or the highdose group ( $\geq 59.4 \mathrm{~Gy}$ ). Overall survival (OS), progression-free survival (PFS) and treatment-related toxicities were assessed and compared between the two groups.

Conclusions: Our findings suggest that higher radiation dose could perform better outcomes for esophageal squamous cell carcinoma patients.

\section{INTRODUCTION}

Esophageal cancer (EC) is a highly lethal malignancy over the world [1, 2]. In East Asia, esophageal squamous cell carcinoma (ESCC) is the most common type, whereas adenocarcinoma is predominant in Western countries. [3]. More than $50 \%$ of patients with EC when diagnosed are at late stages and not amendable at all to major surgery [4]. At present, definitive concurrent chemoradiotherapy (CCRT) is the common strategy for locally advanced inoperable EC patients based on the phase III intergroup trial RTOG 8501, which significantly improved the local control (LC) and overall survival (OS) compared with radiotherapy (RT) alone $[5,6]$. In the landmark INT0123 trial, the results demonstrated that escalating the dose to 64.8 Gy did not confer to a benefit compared with conventional doses, which may lead to a higher incidence of treatment-related toxicity [7]. On the basis of those clinical trials, 50.4 Gy is recommened as the standard radiation dose for definitive treatment to EC. However, the outcomes for patients with EC treated by standard dose radical radiotherapy were still disappointing. Thus, the optimal radiation dose of definitive CCRT for EC remains in debate. Several studies were performed to investigate the 
potential benefit of high dose radiotherapy for EC. Notably, most of the previous study grouping conditions are greater than or less than a threshold dose, such as greater than 60 Gy or less than $60 \mathrm{~Gy}$, greater than 50.4 Gy or less than $50.4 \mathrm{~Gy}$. There is no study explored the efficacy of 59.4 Gy or higher radiotherapy compared with standard dose (50.4) radiotherapy on survival. Thus, we undertook the retrospective study to analyze the survival prognosis of patients who treated with different radiotherapy dose, and attempted to afford new evidences of choosing optimal radiation dose in EC patients treated with radical CRT.

\section{RESULTS}

\section{Patient characteristics}

A total of 137 patients with ESCC treated with CRT were identified, with a median follow-up of 27.5 months (6.4-79.5 months). Of these, 63 patients received standard doses, and 74 received high doses. The general characteristics of the enrolled patients were listed in Table 1. The complete response (CR), partial response (PR) and no-response (NR) rates in the standard-dose group were $39.7 \%(25 / 63), 36.5 \%(23 / 63)$ and $23.8 \%$ $(15 / 63)$, respectively, while the rates were $48.6 \%(36 / 74)$, $36.5 \%(27 / 74)$ and $14.9 \%(11 / 74)$, respectively, in the high-dose group. The $\mathrm{CR}$ in the high-dose group was greater than that the standard-dose group $(48.6 \%$ vs $39.7 \%, P=0.03)$.

\section{Therapy outcomes}

For the entire cohort of patients, the 1-, 2-, and 3 -year PFS rates were $70.0 \%, 29.1 \%$, and $16.0 \%$, respectively, with a median PFS of 16.5 months. As shown in Figure 1, the median PFS was 12.6 months, and the 1-, 2 -, and 3-year PFS rates were 58.0\%, 26.0\% and 12.0\%, respectively, in the standard-dose group; while in the highdose group, the median PFS was 20.0 months, and the 1-, 2 -, and 3-year PFS rates were $80.1 \%, 31.0 \%$ and $20.0 \%$, respectively $(P=0.013)$.

For the entire cohort of patients, the 1-, 2-, and 3-year OS rates were $84.0 \%, 51.0 \%$, and $27.2 \%$, respectively, with a median OS of 25.0 months. The median OS was 19.0 months, and the 1-, 2- and 3-year survival rates were $78.0 \%, 39.0 \%$, and $24.0 \%$, respectively, in the standarddose group; and, in the high-dose group, the median OS was 26.6 months, and the 1-, 2- and 3-year survival rates were $89.0 \%, 61.0 \%$, and $30.0 \%$, respectively $(P=0.037)$ (Figure 2). All endpoints were found to have statistically significant differences favoring the high-dose group.

\section{Toxicity}

Radiation toxicities were mainly esophagitis, hematologic toxicity, and radiation pneumonia. The rate of grade $\geq 3$ radiation esophagitis was much more frequent in the high-dose group ( $10.5 \%$ vs. $2.2 \%$ for the standarddose group, $p<0.01)$. Grade $\geq 3$ radiation pneumonitis occurred in $4 \%$ of patients in the standard-dose group and $6 \%$ of patients in the high-dose group, respectively. There was a trend to increase the treatment-related toxicity, but it was not statistically significant $(p>0.05)$. Furthermore, other toxicities did not differ significantly between groups. There were two treatment-related deaths in the standarddose group (esophageal bleeding, one patient; radiation pneumonitis, one patient) and five treatment-related deaths in the high-dose group (aspiration pneumonia due to trachea-esophageal fistula in 1 to 3 months after $60 \mathrm{~Gy}$, two patient; tumor bleeding in 3 months, three patients).

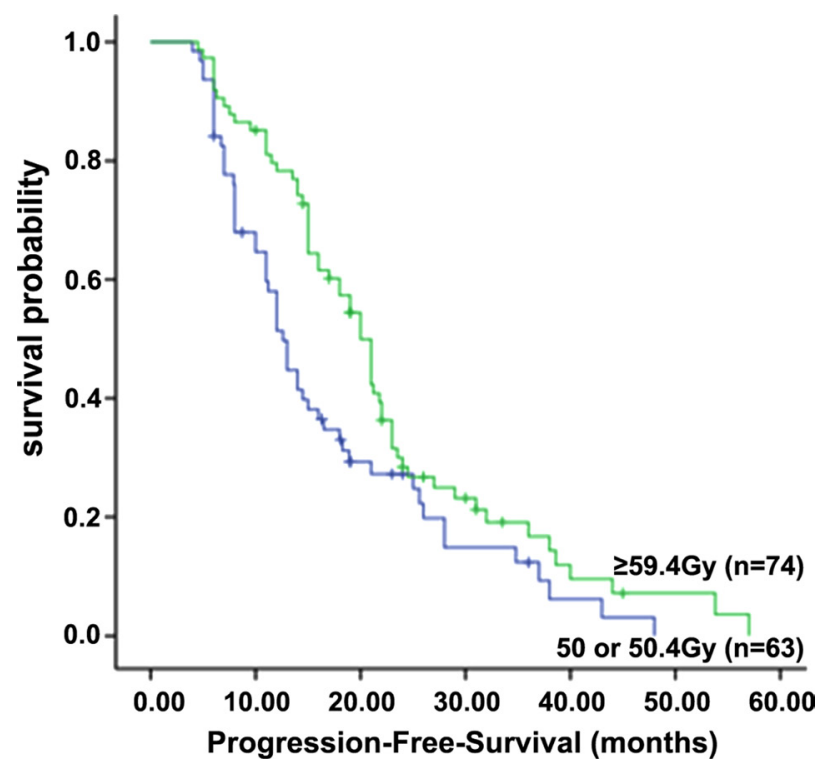

Figure 1: Progression-free survival of patients in the standard-dose group (50 or 50.4 Gy) and high-dose group ( $\geq 59.4$ Gy). 
Table 1: Patient, disease, and treatment characteristics

\begin{tabular}{|c|c|c|c|c|}
\hline Characteristics & Value or No.of Patients (\%) & $\begin{array}{c}\text { Low-Dose Group } \\
\quad(\leq 50.4 \mathrm{~Gy})\end{array}$ & $\begin{array}{l}\text { High-Dose Group } \\
\quad(>50.4 \text { Gy) }\end{array}$ & $P$ value \\
\hline \multicolumn{5}{|l|}{ Age at diagnosis (yr) } \\
\hline Median (range) & $68(36-81)$ & $67(38-79)$ & $68(36-81)$ & \\
\hline \multicolumn{5}{|l|}{ Sex } \\
\hline Male & 95 & 45 & 50 & 0.625 \\
\hline Female & 42 & 18 & 24 & \\
\hline \multicolumn{5}{|l|}{ Smoked at diagnosis } \\
\hline No & 55 & 24 & 31 & 0.651 \\
\hline Yes & 82 & 39 & 43 & \\
\hline \multicolumn{5}{|l|}{ KPS } \\
\hline $90-100$ & 86 & 39 & 47 & 0.846 \\
\hline$\leq 80$ & 51 & 24 & 27 & \\
\hline \multicolumn{5}{|l|}{ Tumor location } \\
\hline Proximal & 29 & 13 & 16 & 0.963 \\
\hline Middle & 57 & 27 & 30 & \\
\hline Distal & 51 & 23 & 28 & \\
\hline \multicolumn{5}{|l|}{ Tumor length $(\mathrm{cm})$} \\
\hline Median (range) & & $5.0(1.0-11.0)$ & $5.0(1.5-13.0)$ & \\
\hline$\leq 5$ & 74 & 35 & 39 & 0.738 \\
\hline$>5$ & 63 & 28 & 35 & \\
\hline \multicolumn{5}{|l|}{ Clinical T status } \\
\hline $\mathrm{T} 1$ & 9 & 4 & 5 & 0.172 \\
\hline $\mathrm{T} 2$ & 37 & 18 & 19 & \\
\hline $\mathrm{T} 3$ & 59 & 27 & 32 & \\
\hline $\mathrm{T} 4$ & 32 & 14 & 18 & \\
\hline \multicolumn{5}{|l|}{ LN status } \\
\hline No & 45 & 29 & 25 & 0.533 \\
\hline N1 & 63 & 31 & 32 & \\
\hline $\mathrm{N} 2$ & 26 & 14 & 12 & \\
\hline N3 & 3 & 2 & 1 & \\
\hline \multicolumn{5}{|l|}{ Clinical stage } \\
\hline I & 4 & 2 & 2 & 0.634 \\
\hline II & 52 & 24 & 26 & \\
\hline III & 81 & 41 & 40 & \\
\hline \multicolumn{5}{|l|}{ Chemotherapy } \\
\hline Induced chemotherapy & 24 & 13 & 11 & 0.811 \\
\hline Concurrent chemotherapy & 65 & 31 & 34 & \\
\hline Sequential chemotherapy & 14 & 6 & 8 & \\
\hline None & 34 & 17 & 17 & \\
\hline \multicolumn{5}{|l|}{$\begin{array}{l}\text { Clinical response of } \\
\text { primary tumor }\end{array}$} \\
\hline Complete response & 61 & 25 & 36 & 0.359 \\
\hline Partial response & 50 & 23 & 27 & \\
\hline None & 26 & 15 & 11 & \\
\hline \multicolumn{5}{|l|}{ Second-line therapy } \\
\hline adjuvant chemotherapy & 95 & 49 & 46 & 0.394 \\
\hline Salvage esophagectomy & 25 & 11 & 14 & \\
\hline Supportive treatment & 17 & 8 & 9 & \\
\hline \multicolumn{5}{|l|}{ RT technique } \\
\hline 3D-CRT & 79 & 38 & 41 & 0.631 \\
\hline IMRT & 58 & 30 & 28 & \\
\hline \multicolumn{5}{|l|}{ PET examination } \\
\hline Yes & 23 & 10 & 13 & 0.578 \\
\hline No & 114 & 56 & 58 & \\
\hline
\end{tabular}

Abbreviations: KPS, karnofsky performance score; LN, lymph node; 3D-CRT, 3 dimensional-conformal radiotherapy; IMRT, intensity-modulated radiotherapy; RT, radiotherapy. 


\section{Prognostic factors}

Patient characteristics were evaluated to determine their prognostic value in the terms of OS (Table 2). According to a univariate analysis, Univariate analysis revealed that smoking status, karnofsky performance status, clinical T stage, and RT dose were found to be significant risk factor. Multivariate analysis revealed that clinical stage, RT dose $\geq 60 \mathrm{~Gy}$, and karnofsky performance status were independent prognostic factors for OS.

\section{DISCUSSION}

During the last three decades, major advances in surgery, RT and chemotherapy have established multimodal approaches as curative treatment options for EC. For patients with inoperable or irresectable diseases, definitive CCRT is the choice of treatment. The NCCN recommended EC radical radiotherapy dose is on the basis of the results of the pivotal study of INT0123 study [7]. However, the study has been criticized due to several drawbacks surround the interpretation of the results. Firstly, the survival between the two groups was influenced by a great deal of complicated deaths among patients in high radiation doses arm (11 vs. 2 deaths). In point of fact, this may not be due to radiation dose escalation as most of deaths in the high radiation doses group occurred before receiving a cumulative dose greater than $50 \mathrm{~Gy}$. Obviously, most of the causes of deaths were related to chemotherapy. Furthermore, a significantly lower dose of 5-FU was administered to patients received radiation dose of $64.8 \mathrm{~Gy}$, which could negatively affect the outcomes of the high-dose arm. Another study conducted by Gaspar et al. also failed to improve the outcomes and resulted in an unacceptably high rate of radiotherapy related toxicity. The standard radiation dose for patients with inoperable
EC receiving definitive chemoradiation therapy has remained 50.4 Gy [8]. Notably, a great deal of studies revealed that the most common recurrence pattern for esophageal cancer after definitive CRT is local-regional recurrence and that a majority of local recurrence occur in the gross tumor volume even for patients achieved complete remission after treatment [9-15]. It indicated that standard dose (50.4 Gy in 28 fractions) was not enough to obtaina higher local control rates. The recommendation of NCCN guidelines for radical radiation dose of $\mathrm{EC}$ was 50 or $50.4 \mathrm{~Gy}$, but the optimal radiation dose of CRT for EC should be reevaluated.

Several studies have attempted to verify the benefit of radiation dose escalation in definitive CRT for locally advanced esophageal cancer. Zhang et al. investigated 69 unresectable or refused resection EC patients who underwent radical CRT, including 43 who received $\leq 51$ Gy and 26 who received $>51$ Gy [16]. They found that patients had a greater 3-year LC (36\% vs. $19 \%$, $p=0.011)$ and disease-free survival (DFS) (25\%vs. $10 \%$, $p=0.004)$ in the high radiation doses arm than those in the low dose group, but that OS was not significantly different $(13 \%$ vs. $3 \%, P=0.054)$. In addition, data from Norway also dose escalation could be beneficial for patients with EC, which could provide a better local control [17]. The OS for patients with higher radiation doseo $f$ definitive CRT was, however, not better than patients receiving lower radiation dose of chemoradiotherapy. Wang et al. retrospectively assessed the outcomes of patients with M0 cervical and upper thoracic esophageal cancer from MD Anderson Cancer Center and demonstrated that patients who received $>50$ Gy experienced greater levels of a CR than patients treated with $<50$ Gy $(79.2 \%$ vs $27.3 \% ; P=0.003$ ) [18]. On multivariable analysis, the radiation dose was the only factor predictive of OS, with improvement in survival in the group receiving $>50 \mathrm{~Gy}$.

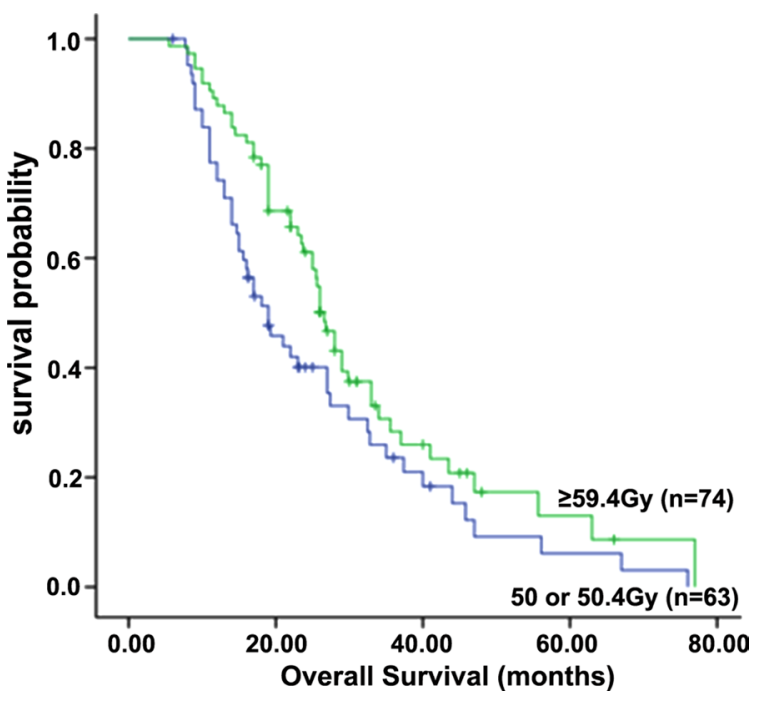

Figure 2: Overall survival of patients in the standard-dose group ( 50 or $50.4 \mathrm{~Gy})$ and high-dose group ( $\geq 59.4 \mathrm{~Gy})$. 
Table 2: Univariate and multivariate analysis of prognostic factors for OS

\begin{tabular}{lcccccc}
\hline Factors & \multicolumn{3}{c}{ Univariate analysis } & \multicolumn{3}{c}{ Multivariate analysis } \\
\cline { 2 - 7 } & HR & $\mathbf{9 5 \%}$ CI & $\boldsymbol{P}$ & HR & $\mathbf{9 5 \%}$ CI & $\boldsymbol{P}$ \\
\hline Age $(\geq 60)$ & 0.83 & $0.41-1.62$ & 0.53 & & & \\
Sex (Male) & 0.683 & $0.39-1.27$ & 0.226 & & & \\
Smoking status (No) & 0.52 & $0.25-0.93$ & 0.037 & 1.143 & $0.74-1.72$ & 0.532 \\
KPS ( $\geq$ 90) & 0.41 & $0.24-0.70$ & $<0.01$ & 0.39 & $0.21-0.68$ & $<0.01$ \\
Tumor location (Distal) & 0.63 & $0.33-1.19$ & 0.14 & & & \\
Tumor length ( $\leq 5 \mathrm{~cm})$ & 0.788 & $0.49-1.28$ & 0.334 & & & \\
Tumor stage (T1-T3) & 0.691 & $0.48-0.96$ & 0.045 & 0.663 & $0.45-0.94$ & 0.031 \\
LN status (No) & 0.50 & $0.24-1.04$ & 0.07 & & & \\
RT dose ( $\geq$ 59.4) & 0.43 & $0.25-0.81$ & 0.01 & 0.40 & $0.23-0.77$ & $<0.01$ \\
\hline
\end{tabular}

Table 3: High-dose versus standard-dose radiotherapy for ESCC

\begin{tabular}{|c|c|c|c|c|c|c|c|}
\hline References & $\begin{array}{l}\text { Radiation } \\
\text { dose }\end{array}$ & Radiation technique & $n$ & LC & $P$ value & OS & $P$ value \\
\hline Minsky et al.[7] & $\begin{array}{l}50.4 \mathrm{~Gy} \\
64.8 \mathrm{~Gy}\end{array}$ & Conventional RT & $\begin{array}{l}109 \\
109\end{array}$ & $\begin{array}{l}46 \% \\
48 \%\end{array}$ & $>0.05$ & $\begin{array}{l}40 \% \text { (2 year) } \\
31 \%\end{array}$ & $>0.05$ \\
\hline Zhang et al. [16] & $\begin{array}{l}<51 \mathrm{~Gy} \\
\geq 51 \mathrm{~Gy}\end{array}$ & Conventional RT & $\begin{array}{l}43 \\
26\end{array}$ & $\begin{array}{l}19 \% \\
36 \%\end{array}$ & 0.011 & $\begin{array}{l}3 \% \text { (3year) } \\
13 \%\end{array}$ & 0.054 \\
\hline Hurmuzlu et al. [17] & $\geq 60 \mathrm{~Gy}$ & Conventional RT & 46 & 33 months (MST) & - & $22 \%$ (2 year) & - \\
\hline Wang et al. [18] & $\begin{array}{l}<50 \mathrm{~Gy} \\
>50 \mathrm{~Gy}\end{array}$ & $\begin{array}{l}\text { Conventional RT } \\
\text { or 3D-CRT }\end{array}$ & $\begin{array}{l}11 \\
24\end{array}$ & $\begin{array}{l}47.7 \% \text { (whole } \\
\text { group) }\end{array}$ & 0.001 & $\begin{array}{l}0 \%(5 \text { year }) \\
29 \%\end{array}$ & 0.002 \\
\hline Suh et al. [19] & $\begin{array}{l}<60 \mathrm{~Gy} \\
\geq 60 \mathrm{~Gy}\end{array}$ & Conventional RT & $\begin{array}{l}49 \\
77\end{array}$ & $\begin{array}{l}32 \% \\
69 \%\end{array}$ & $<0.01$ & $\begin{array}{l}18 \text { mons (MST) } \\
28 \text { mons }\end{array}$ & 0.26 \\
\hline He et al. [20] & $\begin{array}{l}\leq 50.4 \mathrm{~Gy} \\
>50.4 \mathrm{~Gy}\end{array}$ & 3D-CRT & $\begin{array}{c}137 \\
56\end{array}$ & $\begin{array}{l}34.3 \% \text { (LFR) } \\
17.9 \%\end{array}$ & 0.024 & $\begin{array}{l}33.0 \% \text { ( } 5 \text { year }) \\
41.7 \%\end{array}$ & 0.617 \\
\hline Kim et al. [21] & $\begin{array}{l}<60 \mathrm{~Gy} \\
\geq 60 \mathrm{~Gy}\end{array}$ & 3D-RT or IMRT & $\begin{array}{l}120 \\
116\end{array}$ & $\begin{array}{l}37.3 \% \\
59.7 \%\end{array}$ & 0.02 & $\begin{array}{l}22.3 \text { mons (MST) } \\
35.1 \text { mons }\end{array}$ & 0.043 \\
\hline
\end{tabular}

Abbreviations: LC, local control; RT, radiotherapy; MST, median survival time; OS, overall survival; LRF, Local failure rate.

In the retrospective analysis by Suh YG and colleagues, the results also showed patients who received a total dose $\geq 50.4$ Gy of RT had significantly better LRC $(69 \%$ vs. $32 \%, p<0.01)$ and PFS (47\% vs. $20 \%, p=0.01)$, than patients receiving $<50$ Gy when treated with concurrentchemotherapy. High-dose radiation $\geq 50.4$ Gy showed no significant OS benefit for patients with EC ( 28 vs. 18 months, $p=0.26$ ) [19]. More recently, additional retrospective analyses from MD Anderson Cancer Center reported outcomes from a cohort of 193 patients with ESCC underwent radical concurrent chemotherapy and radiation therapy using modern techniques [20]. The results showed that high radiation dose provided a significant lower rate of local recurrence $(17.9 \%$ vs $34.3 \%, p=0.024)$ compared to patients receiving low radiation dose. Furthermore, patients receiving high radiation did have a marginal better 5-year local regional recurrence-free survival $(68.7 \%$ vs $55.9 \%, p=0.052)$ than low-dose group. The 5 -year overall survival rate was no significant differences between the two groups $(p=0.617)$.It revealed that high radiation doses improved tumor local control but could not bring a survival benefit for patients with ESCC.A retrospective analysis performed by Kim et al was conducted to investigate the outcomes that high radiation did canbring a survival benefit for
EC patients treated with CRT [21]. The results showed that patients receiving high radiation dose had a greater 2-year LRC (69.1\% vs. 50.3\%, $p=0.002$ ), median PFS (16.7 vs. 11.7 months, $p=0.029$ ), and median survival time (35.1 vs. 22.3 months, $p=0.043$ ) than the low-dose group. The optimal radiation dose of radical CRT for EC, however, is still not definite (as summaried in Table 3). These conflicting results could be potentially attributed to differences in patient populations, tumor histology types, grouping criteria, as well as treatment.

In our study, homogenous histologic type of ESCC was included and all patients received similarly chemotherapy regimens. Our study showed that higher radiation dose brings a survival benefit to stage II-III ESCC patients treated with definitive CRT. The results revealed that both progression free survival and median survival in the high radiation dose arm are longer than that in the conventional radiation dose arm. The 1-, 2-, and 3-year PFS rates in the high-dose group were higher in high radiation dose arm than that in the standarddose arm. It is the same to the median OS. With regard to toxicity, the rate of grade $\geq 3$ acute and late radiation related toxicity seem to be high in the landmark INT0123 trial. Recently, several studies used modern radiotherapy technique have report that the rate of grade $\geq 3$ radiation 
esophagitis and radiation pneumonitis were about 1 $0.8 \%-18 \%$ and $3.3 \%-6 \%$ in EC patients treated with CRT [16-21]. In our study, the incidence of grade 3 or higher radiation esophagitis was higher in the high radiation dose arm than that in the standard radiation dose arm (10.5 vs.2.2\%, $p<0.01)$. The incidence of grade greater than or equal to 3 radiation pneumonitis during and after completing the treatment were $4 \%$ in the group received a standard dose $(50.4 \mathrm{~Gy})$ and $6 \%$ in the group received a higher dose of $\operatorname{RT}(\geq 59.4$ Gy). In addition, there was no significant difference between the two groups in terms of other treatment-related toxicities. The Adverse event rates seem to be low in our study. This may explained by that the radiation technique used in previous studies were twodimensional, and the margins applied to the target volume were larger than those used in current practice, which may have increased the probability of toxicities. However, in our study, the application of precision radiotherapy and simultaneous modulated accelerated radiotherapy, which can reduce incidences of treatment toxicities. Moreover, nearly half of the patients received involvedfield radiotherapy (IFRT), and studies showed that IFRT lead to reduce treatment toxicities without sacrificing overall survival in patients with EC [22-25]. In addition, the follow-up time of some patients in the current study was not long enough. Observation period is not sufficient for evaluating the overall effects of CRT. The results of our study indicated that patients who received radiation doses in excess of 59.4 Gy would have significantly better PFS, and OS than patients receiving standard dose (50-50.4 Gy) when treated with concurrent chemotherapy, which are similar to the results of Kim and colleague [21].

There are limitations to our approach in this study. First, it was a retrospective study, and our data originated from a single institution. Furthermore, the data of radiation planning parameters, including field size, which may have influenced the outcomes. Finally, it is possible that treatment-related toxicities were underestimated due to the study's retrospective setting.

\section{MATERIALS AND METHODS}

\section{Patient characteristics}

We retrospectively reviewed non-operated localized ESCC patients who received CCRT with external beam radiotherapy and diagnosed within 2010-2014. All patients had histologically proven primary ESCC. Between May 2010 and May 2014, a total of 366 patients with ESCC were treated by CCRT at our institutions. Patients were excluded from this analysis for the following reasons: (1) patients received radiotherapy with palliative intent ( $n=78)$; (2) they underwent esophagectomy after CRT $(n=46)$; (3) patients did not receive complete treatment $(n=49)$; (4) follow-up loss after CRT $(n=44)$ and (5) they had prior malignancies $(n=22)$. Ultimately, the medical records of total 137 patients treated with CCRT were retrospectively reviewed for this study. The electronic medical records of those patients were retrospectively reviewed. Pretreatment investigations included medical history, physical examination, symptoms, performance status, complete blood count, measurement of serum electrolytes, CT of the neck, chest and abdomen, bone scan, endoscopy, and esophagography. Part of patients underwent 18F-fluorodeoxyglucose positron emission tomography (FDG-PET). The clinical stage was assigned according to the 7 th American Joint Committee on Cancer (AJCC) staging system. Patients were stratified by the total radiation dose, with the high-dose group receiving $\geq 59.4$ Gy and the standard dose group by 50 or 50.4 Gy.

\section{Treatment approaches}

All patients underwent radiotherapy delivered by three-dimensional conformal radiation therapy or intensity-modulated radiation therapy technique. Patients were treated 5 days per week at 1.8-2.0 Gy. The gross tumor volume (GTV) was delineated based on CT, barium esophagogram, endoscopic examination, and PET imaging. The clinical target volume (CTV) consisted of clinical target volume (CTVt) (the gross tumor volume) and nodal CTV. The CTVt included the gross primary tumor volume with a radial margin of 0.5 to $1 \mathrm{~cm}$ and a proximal and distal margin of 3 to $5 \mathrm{~cm}$. The nodal CTV was defined by a 0.5 to $0.8 \mathrm{~cm}$ expansion around the nodal gross tumor volume and some patients also covered the regional nodal regions. The planning target volume (PTV) was the CTV plus a uniform $0.5-\mathrm{cm}$ expansion margin. For both the standard-dose group (50 or $50.4 \mathrm{~Gy}$ ) and high-dose ( $\geq 59.4$ Gy) groups, prescribed dose is given to the PTV. Chemotherapy consisted of two cycles of platinum-based chemotherapy combined with 5-fluorouracil and a taxane (docetaxel or paclitaxel). In the whole group, 103 (75.2\%) patients underwent chemotherapy, including induction chemotherapy (23.3\%), concurrent chemotherapy (63.1\%), and sequential chemotherapy $(13.6 \%)$. Among the patients who underwent chemotherapy, $53(51.5 \%)$ were in the highdose group and $50(48.5 \%)$ were in the standard-dose group.

\section{Assessment of response and toxicity}

Tumor response was evaluated according to the Response Evaluation Criteria in Solid Tumors (RECIST) system [26]. Treatment-related toxicities were recorded according to the common toxicity criteria for adverse events (version 3.0) [27]. The observation started from the date of treatment to the date of death or the last follow-up.

\section{Follow-up}

All patients were examined weekly during RT to monitor treatment toxicities and their general condition. Routine evaluations included physical exam, hematologic 
and biochemical profiles, and esophagography. The patients were evaluated at 1 month after RT. Thereafter, the patients were asked to visit our clinic at 3-month intervals for the first 2 years, and then at every 6 months' interval. The follow-up evaluations included physical examination, esophagography, esophagogastroduodenoscopy, chest and abdominal CT and positron emission tomography (PET) when available. Other necessary examinations were conducted according to the clinical situation.

\section{Definition of event}

OS was measured from the first day of treatment to the date of death from any cause or the last known date that the patient was alive. PFS was defined as the duration from the date of treatment to the date of failure, either the date of death from any cause or the date of the last known follow-up.

\section{Statistical analysis}

Statistical analyses were carried out using SPSS (version 19.0). Comparisons of patient characteristics and toxicities were performed with Chi-square (and Fisher's exact) test. OS and PFS were calculated using the KaplanMeier method, and the log-rank test was employed to evaluate the difference in survival curves between the two groups. Multivariate analysis for OS was performed using Cox regression. Statistical tests were based on a two-sided significance level, and $p$ values of less than 0.05 were considered significant.

\section{CONCLUSIONS}

In summary, the results of our study revealed that stage II-III patients who delivery of radiation dose above the current standard 50.4 Gy could prolong survival time, including PFS and OS. Although modern radiation techniques could ensure the safety and effectiveness of delivering higher radiation doses, controversies still exist about the optimal radiation dose for patients with ESCC undergoing radical treatment. Thus, in the future, randomized prospective clinical studies are needed to verify the effect of radiation dose escalation of CCRT for EC.

\section{CONFLICTS OF INTEREST}

The authors report no conflicts of interest in this work.

\section{REFERENCES}

1. Torre LA, Bray F, Siegel RL, Ferlay J, Lortet-Tieulent J, Jemal A. Global cancer statistics, 2012. CA Cancer J Clin. 2015; 65:87-108.
2. Ferlay J, Shin HR, Bray F, Forman D, Mathers C, Parkin DM. Estimates of worldwide burden of cancer in 2008: GLOBOCAN 2008. Int J Cancer. 2010; 127:2893-917.

3. Wheeler JB, Reed CE. Epidemiology of esophageal cancer. Surg Clin North Am. 2012; 92:1077-87.

4. Shahbaz Sarwar CM, Luketich JD, Landreneau RJ, Abbas G. Esophageal cancer: an update. Int J Surg. 2010; 8:417-22.

5. Herskovic A, Martz K, al-Sarraf M, Leichman L, Brindle J, Vaitkevicius V, Cooper J, Byhardt R, Davis L, Emami B. Combined chemotherapy and radiotherapy compared with radiotherapy alone in patients with cancer of the esophagus. N Engl J Med. 1992; 326:1593-8.

6. Cooper JS, Guo MD, Herskovic A, Macdonald JS, Martenson JA Jr, Al-Sarraf M, Byhardt R, Russell AH, Beitler JJ, Spencer S, Asbell SO, Graham MV, Leichman LL. Chemoradiotherapy of locally advanced esophageal cancer: long-term follow-up of a prospective randomized trial (RTOG 85-01). Radiation Therapy Oncology Group. JAMA. 1999; 281:1623-7.

7. Minsky BD, Pajak TF, Ginsberg RJ, Pisansky TM, Martenson J, Komaki R, Okawara G, Rosenthal SA, Kelsen DP. INT 0123 (Radiation Therapy Oncology Group 94-05) phase III trial of combined-modality therapy for esophageal cancer: high-dose versus standard-dose radiation therapy. J Clin Oncol. 2002; 20:1167-74.

8. Gaspar LE, Winter K, Kocha WI, Coia LR, Herskovic A, Graham M. A phase I/II study of external beam radiation, brachytherapy, and concurrent chemotherapy for patients with localized carcinoma of the esophagus (Radiation Therapy Oncology Group Study 9207): Final report. Cancer 2000; 88:988-95.

9. Bedenne L, Michel P, Bouché O, Milan C, Mariette C, Conroy T, Pezet D, Roullet B, Seitz JF, Herr JP, Paillot B, Arveux P, Bonnetain F, et al. Chemoradiation followed by surgery compared with chemoradiation alone in squamous cancer of the esophagus: FFCD 9102. J Clin Oncol. 2007; 25:1160-8.

10. Rawat S, Kumar G, Kakria A, Sharma MK, Chauhan D. Chemoradiotherapy in the management of locally advanced squamous cell carcinoma esophagus: is surgical resection required? J Gastrointest Cancer. 2013; 44:277-84.

11. Pöttgen C, Stuschke M. Radiotherapy versus surgery within multimodality protocols for esophageal cancer - a metaanalysis of the randomized trials. Cancer Treat Rev. 2012; 38:599-604.

12. Kawaguchi Y, Nishiyama K, Miyagi K, Suzuki O, Ito Y, Nakamura S. Patterns of failure associated with involved field radiotherapy in patients with clinical stage I thoracic esophageal cancer. Jpn J Clin Oncol. 2011; 41:1007-12.

13. van Hagen P, Hulshof MC, van Lanschot JJ, Steyerberg EW, van Berge Henegouwen MI, Wijnhoven BP, Richel DJ, Nieuwenhuijzen GA, Hospers GA, Bonenkamp JJ, Cuesta MA, Blaisse RJ, Busch OR, et al. Preoperative chemoradiotherapy for esophageal or junctional cancer. $\mathrm{N}$ Engl J Med. 2012; 366:2074-84. 
14. Kato K, Nakajima TE, Ito Y, Katada C, Ishiyama H, Tokunaga SY, Tanaka M, Hironaka S, Hashimoto T, Ura T, Kodaira T, Yoshimura K. Phase II study of concurrent chemoradiotherapy at the dose of 50.4 Gy with elective nodal irradiation for Stage II-III esophageal carcinoma. Jpn J Clin Oncol. 2013; 43:608-15.

15. Rohatgi PR, Swisher SG, Correa AM, Wu TT, Liao Z, Komaki R, Walsh G, Vaporciyan A, Lynch PM, Rice DC, Roth JA, Ajani JA. Failure patterns correlate with the proportion of residual carcinoma after preoperative chemoradiotherapy for carcinoma of the esophagus. Cancer. 2005; 104:1349-55.

16. Zhang Z, Liao Z, Jin J, Ajani J, Chang JY, Jeter M, Guerrero T, Stevens CW, Swisher S, Ho L, Yao J, Allen P, Cox JD, et al. Dose-response relationship in locoregional control for patients with stage II-III esophageal cancer treated with concurrent chemotherapy and radiotherapy. Int J Radiat Oncol Biol Phys. 2005; 61:656-64.

17. Hurmuzlu M1, Monge OR, Smaaland R, Viste A. High-dose definitive concomitant chemoradiotherapy in non-metastatic locally advanced esophageal cancer: Toxicity and outcome. Dis Esophagus. 2010; 23:244-52.

18. Wang S, Liao Z, Chen Y, Chang JY, Jeter M, Guerrero T, Ajani J, Phan A, Swisher S, Allen P, Cox JD, Komaki R. Esophageal cancer located at the neck and upper thorax treated with concurrent chemoradiation: a single-institution experience. J Thorac Oncol. 2006; 1:252-9.

19. Suh YG, Lee IJ, Koom WS, Cha J, Lee JY, Kim SK, Lee CG. High-dose versus standard-dose radiotherapy with concurrent chemotherapy in stages II-III esophageal cancer. Jpn J Clin Oncol. 2014; 44:534-40.

20. He L, Allen PK, Potter A, Wang J, Chang JY, Gomez DR, Komaki R, Liao Z, Lin SH. Re-evaluating the optimal radiation dose for definitive chemoradiotherapy for esophageal squamous cell carcinoma. J Thorac Oncol. 2014; 9:1398-405.

21. Kim HJ, Suh YG, Lee YC, Lee SK, Shin SK, Cho BC, Lee CG. Dose-response Relationship Between Radiation dose and Loco-regional Control in Patients with Stage II-III Esophageal Cancer Treated with Definitive Chemoradiotherapy. Cancer Res Treat. 2016. https://doi. org/10.4143/crt.2016.354.

22. Zhao KL, Ma JB, Liu G, Wu KL, Shi XH, Jiang GL. Three-dimensional conformal radiation therapy for esophageal squamous cell carcinoma: is elective nodal irradiation necessary. Int J Radiat Oncol Biol Phys. 2010; 76:446-51.

23. Button MR, Morgan CA, Croydon ES, Roberts SA, Crosby TD. Study to determine adequate margins in radiotherapy planning for esophageal carcinoma by detailing patterns of recurrence after definitive chemoradiotherapy. Int J Radiat Oncol Biol Phys. 2009; 73:818-23

24. Zhang X, Li M, Meng X, Kong L, Zhang Y, Wei G, Zhang X, Shi F, Hu M, Zhang G, Yu J. Involved-field irradiation in definitive chemoradiotherapy for locally advanced esophageal squamous cell carcinoma. Radiat Oncol. 2014; 9:64.

25. Yamashita H, Takenaka R, Omori M, Imae T, Okuma K, Ohtomo K, Nakagawa K. Involved-field radiotherapy (IFRT) versus elective nodal irradiation (ENI) in combination with concurrent chemotherapy for 239 esophageal cancers: a single institutional retrospective study. Radiat Oncol. 2015; 10:171.

26. Eisenhauer EA, Therasse P, Bogaerts J, Schwartz LH, Sargent D, Ford R, Dancey J, Arbuck S, Gwyther S, Mooney M, Rubinstein L, Shankar L, Dodd L, et al. New response evaluation criteria in solid tumours: revised RECIST guideline (version 1.1). Eur J Cancer. 2009; 45:228-47.

27. Trotti A, Colevas AD, Setser A, Rusch V, Jaques D, Budach V, Langer C, Murphy B, Cumberlin R, Coleman CN, Rubin P. CTCAE v3.0: development of a comprehensive grading system for the adverse effects of cancer treatment. Semin Radiat Oncol. 2003; 13:176-81. 